\title{
Shaping the Brazilian landscape: a process drive by land occupation, large-scale deforestation, and rapid agricultural expansion
}

Leandro Parente ( $\sim$ leandro.parente@opengeohub.org )

OpenGeoHub Foundation

\section{Ana Paula Mattos}

Universidade Federal de Goiás

Luis Baumann

Universidade Federal de Goiás

Vanessa Lopes

Brazilian Institute of Geography and Statistics

Elaine Barbosa Silva

Universidade Federal de Goiás

Sérgio Nogueira

Universidade Federal de Goiás

Vinícius Vieira Mesquita

Universidade Federal de Goiás

Laerte Guimarães Ferreira

Universidade Federal de Goiás

\section{Research Article}

Keywords: natural, land, annual, brazil, world, study

Posted Date: August 19th, 2021

DOI: https://doi.org/10.21203/rs.3.rs-819697/v1

License: (1) (1) This work is licensed under a Creative Commons Attribution 4.0 International License.

Read Full License 


\title{
Shaping the Brazilian landscape: a process driven by land occupation, large-scale deforestation, and rapid agricultural expansion
}

\author{
Leandro Leal Parente ${ }^{1,2, *}$, Ana Paula Mattos ${ }^{1}$, Luis Baumann ${ }^{1,3}$, Vanessa Lopes ${ }^{4}$, Elaine \\ Barbosa da Silva $^{1}$, Sérgio Nogueira ${ }^{1}$, Vinícius Vieira Mesquita ${ }^{1}$, and Laerte Guimarães \\ Ferreira $^{1}$ \\ ${ }^{1}$ Federal University of Goiás (UFG), Image Processing and GIS Laboratory (LAPIG), Goiânia, 74001-970, Brazil \\ ${ }^{2}$ OpenGeoHub Foundation, Wageningen, 6708PW, The Netherlands \\ ${ }^{3}$ Federal University of Goiás (UFG), Institute of Mathematics and Statistics (IME), Goiânia, 74001-970, Brazil \\ ${ }^{4}$ Brazilian Institute of Geography and Statistics (IBGE), Goiânia, 74043-020, Brazil \\ *leandro.parente@opengeohub.org
}

12 ABSTRACT

Brazil is one of the largest food producers in the world, a leading role that prompted a profound process of anthropization of its landscapes. Knowing the dynamics and dimension of these transformations is essential for a more efficient and sustainable use of the country's natural resources. Thus, in this study we present, based on an unprecedented sample design and interpretation of 85,152 sample points in Landsat images, the area estimates of the main land cover and land use classes in Brazil, as well as their annual transitions, from 1985 to 2018 . Our results indicate that, of the 850 Mha that comprise the national territory, 294.2 Mha $\pm 1.44 \%$ were anthropized in 2018 , with $\sim 34 \%$ of this area converted after 1985 . In this period, there was a loss of $1398.2 \mathrm{Mha} \pm 2.27 \%$ of natural vegetation, and an increase of $55.1 \mathrm{Mha} \pm 0.64 \%$ in the pasture areas and $28.2 \mathrm{Mha} \pm 0.29 \%$ in the areas of annual crops. The transition analysis showed that $83.07 \mathrm{Mha} \pm 1.31 \%$ of pastures and $9.64 \mathrm{Mha} \pm 0.45 \%$ of agriculture (annual, semi-perennial, and perennial combined) occurred over natural vegetation, $18.12 \mathrm{Mha} \pm 0.63 \%$ of pastures were converted to agriculture, while another $9.7 \mathrm{Mha} \pm 0.45 \%$ were abandoned, which can serve as important land reserves for other uses. The vast public dataset, approaches (simple, robust, and straightforward), codes and tools (open and available) utilized in this study can be easily employed in any other region of the world, in support of environmental monitoring and improved territorial governance practices.

\section{Introduction}

The increase in the global demand for food has promoted Brazil to a prominent role as one of the largest grain and beef producers in the world ${ }^{1,2}$. The soy produced in the country represents $23.4 \%$ of the global production and $30.6 \%$ of the global exports ${ }^{3}$, being an important vector of economic, social, and environmental transformations in the country's recent history. Thus, intense changes in land use and land cover, triggered by state and private actions, occurred from the 1970s onwards ${ }^{4}$. In the Cerrado biome, for example, agricultural expansion resulted in the suppression of more than $50 \%$ of the native vegetation cover and the fragmentation of a large portion of its remnants, as well as socio-territorial impacts, such as the migration of a large part of the rural population for cities ${ }^{5,6}$. Another biome heavily impacted by agricultural expansion was the Amazon ${ }^{7-10}$, with the incidence of a similar conversion process of native vegetation in pasture and soybean intensified from the 1980s.

Considering the effects of these actions and global climate change ${ }^{11,12}$, the territorial governance that prioritizes environmentally sustainable agricultural production and the execution of environmental policies that seek to the conservation of natural resources become even more important. In this context, a great ally in the formulation and monitoring of these policies are land use and land cover data. They ensure greater efficiency in economic, social, and environmental diagnoses, supporting the prioritization of actions and goals in the short, medium, and long term.

Much of the data that quantify the areas occupied by native vegetation, agriculture, and other land uses in the Brazilian territory are derived from census estimates or produced from satellite data. These include public efforts such as the Agricultural Census, the Municipal Agricultural Research (PAM), the mappings produced by the Brazilian Institute of Geography and Statistics (IBGE), programs coordinated by the Ministry of the Environment (e.g. Probio and Terraclass), in addition to monitoring systems for the suppression of native vegetation in the Brazilian biomes, coordinated by the National Institute for Space Research (INPE) (i.e. PRODES and DETER ${ }^{5,13}$ ). 
These mappings and monitoring systems have in common the production of data from the visual inspection of satellite images, involving high costs for relatively short time frames. Recently, with the increase in computational capacity for processing and storing data, some mappings for the Brazilian territory started to be carried out using machine learning algorithms, including initiatives such as Mapbiomas ${ }^{7}$ and Global Forest Watch ${ }^{14,15}$. Although spatially explicit, such mappings should not be used, directly and as the only data source, to estimate land use and land cover areas and their respective transitions, since classification errors result in biased estimates ${ }^{16}$.

Alternatively, such area estimates should consider point samples, supported by sampling designs and labeled by visual inspection of satellite images ${ }^{17,18}$ or field surveys ${ }^{14,19}$. Such approaches, however, are not free from the bias of subjectivity and the criteria of each interpreter, the occurrence of eventual georeferencing errors or, depending on the image resolution, the presence of pixels with spectral mixing ${ }^{20}$. On the other hand, the synergy between spatially explicit mappings, based on the use of automated classifiers, and point samples is necessary, either for validation purposes or for area adjustments $5,14,19,20$.

With regard to the use of point samples, the option for stratified sampling is frequent, whose strata are defined by existing mappings, which may or may not correspond to the classes of interest ${ }^{9,18,21,22}$. In this context, this work presents, based on point samples derived from the interpretation of Landsat images, the estimate of the total area of 13 land cover and land use classes in Brazil between 1985 and 2018. For this endeavor, we adopted an unprecedented sample design, which, while consistent with the stratification assumptions, proved to be sufficiently robust and spatially stable over time, thus allowing area estimates of land use and land cover changes, specifically concerning deforestation and agricultural expansion, on a national scale and for all the Brazilian biomes.

\section{Results}

\section{Land Use and Land Cover Dynamics}

Land use and land cover area estimates revealed a gross loss of 49.1 Mha $\pm 0.73 \%$ of forest formations, $43.3 \mathrm{Mha} \pm 0.53 \%$ of savanna formations, and $12.5 \mathrm{Mha} \pm 0.37 \%$ of grassland formations between 1985 and 2018 , a total of $104.8 \mathrm{Mha} \pm 1.63 \%$ of natural vegetation (Figure 1a). In relative numbers, savanna formations were the most affected, with a $30.4 \% \pm 0.53 \%$ reduction in vegetation cover based on the initial year of analysis (1985), followed by grassland formations with $21.4 \% \pm 0.37 \%$, and forest formations with $11.4 \% \pm 0.73 \%$ reduction in the same period. Areas of other non-forest formations, located mostly in the Amazon biome, remained stable, with variations in the initial and final years caused by samples labeled as "not observed" due to the high occurrence of clouds in the region, a problem that is also observed in the estimates of forest formations.

With regard to land use estimates, there was an area increase of $55.1 \mathrm{Mha} \pm 0.64 \%$ for pasture, $28.2 \mathrm{Mha} \pm 0.29 \%$ for annual crop, 7.7 Mha $\pm 0.14 \%$ for semi-perennial crop, $7.5 \mathrm{Mha} \pm 0.15 \%$ for tree plantation, and 2.1 Mha $\pm 0.10 \%$ for perennial crop (Figure 1). Although the largest increase in area was associated with the expansion of pastures, in relative numbers this was the land use with the lowest relative percentage of expansion with reference to 1985 , equivalent to $34.5 \% \pm 0.64 \%$, while practically all other land uses have doubled the area of occupation between 1985 and 2018. The relative increase of perennial crops was equivalent to $99.1 \% \pm 0.10 \%$, of annual crops was $156.4 \% \pm 0.29 \%$, of tree plantation was $173.2 \% \pm 0.15 \%$, and of $183.6 \%$ $\pm 0.14 \%$ for semi-perennial crops.

Specifically on the urban infrastructure estimates, there was an absolute area increase of 1.7 Mha $\pm 0.11 \%$ and a relative increase of $57.3 \% \pm 0.11 \%$ over the 34 years evaluated (Figure 1b). The annual expansion of these areas showed the same trend as the expansion of perennial crops. The country's water surface increased $1.3 \mathrm{Mha} \pm 0.18 \%$ in absolute numbers and $10.2 \%$ $\pm 0.18 \%$ in relative terms, while the wetlands area decreased by 0.26 Mha $\pm 0.10 \%$ in absolute numbers and $8.6 \% \pm 0.10 \%$ in figures relative to 1985 . The absolute area occupied by the "Other" class (i.e. rocky outcrop, apicum, aquaculture, mangrove, mining, other non-vegetated areas, beaches and dunes) increased by 0.9 Mha $\pm 0.11 \%$ and by $23.1 \% \pm 0.11 \%$ in relative numbers.

\section{Historical Deforestation}

Estimates of primary deforestation (i.e. first event of vegetation suppression considering a predefined baseline year) revealed a total accumulated area equivalent to $98.2 \mathrm{Mha} \pm 2.27 \%$, of which $52.7 \mathrm{Mha} \pm 0.99 \%$ occurred in forest formations, 35.03 Mha $\pm 0.82 \%$ in savanna formations, and $10.4 \mathrm{Mha} \pm 0.46 \%$ in grassland formations, between 1988 and 2018 (Figure 2a). Despite the general downward trend in deforestation estimates in the period evaluated, in $2018,1.9$ Mha $\pm 0.05 \%$ of natural vegetation cover was suppressed, mostly affecting forest formations. The years 1989 and 2003 presented the highest estimates of primary deforestation in the period, with areas equivalent to $5.79 \mathrm{Mha} \pm 0.10 \%$ and $5.03 \mathrm{Mha} \pm 0.09 \%$, respectively.

With regard to the Brazilian biomes (Figure 2b), the Amazon was the most affected biome, with $37.2 \mathrm{Mha} \pm 1.96 \%$ of total primary deforestation between 1988 and 2018, followed by the Cerrado biome with 36.9 Mha $\pm 3.23 \%$. This total was 5.4 Mha $\pm 2.0 \%$ and $11.8 \mathrm{Mha} \pm 4.1 \%$ for the Atlantic Forest and Caatinga, respectively. Despite the downward trend in the period, the Pampa and Pantanal showed relative stability in areas of primary deforestation, with an annual average of $\sim 162,068$ ha and $\sim 70,344$ ha, respectively, in the 34 years evaluated. 


\section{Agricultural Expansion}

Our results indicated an increase of $83.07 \mathrm{Mha} \pm 1.31 \%$ of pastures and 9.64 Mha $\pm 0.45 \%$ of agriculture (annual, semi-perennial and perennial combined) over natural vegetation, while $105.2 \mathrm{Mha} \pm 0.25 \%$ and $16.6 \mathrm{Mha} \pm 0.16 \%$ of pastures and agriculture, respectively, remained with stable use between 1986 and 2018 (Figure 3a). Of the existing pastures in 1986, 18.12 Mha $\pm 0.63 \%$ were converted to crops and 9.7 Mha $\pm 0.45 \%$ were abandoned, showing a high presence of secondary vegetation in 2018 . Most of the expansion of pastures occurred in the Amazon, equivalent to 33.9 Mha $\pm 1.98 \%$ (Figure $3 \mathrm{~b}$ ), followed by 30.7 Mha $\pm 3.08 \%$ in the Cerrado (Figure 3c). On the other hand, most of Brazil's crop expansion has taken place in the Cerrado, equivalent to $13.05 \mathrm{Mha} \pm 2.81 \%$, with $\sim 60 \%$ being over pasture areas and the rest over natural vegetation. In the Atlantic Forest, $\sim 94 \%$ of the crop expansion occurred over pastures, equivalent to 9.1 Mha $\pm 2.69 \%$ (Figure $3 \mathrm{~d}$ ), while in the Pampa, $2.84 \mathrm{Mha}$ $\pm 9.02 \%$ occurred over natural vegetation (Figure 3f), mostly in grassland formations. In the Caatinga and Pantanal, pasture expansion occurred over 11.6 Mha $\pm 4.28 \%$ (Figure 3e) and 2.19 Mha $\pm 9.63 \%$ (Figure $3 \mathrm{~g}$ ) of natural vegetation, respectively, affecting mainly the savanna and grassland formations in these biomes.

\section{Discussion}

The data produced by this study show that, between 1985 and 2018, Brazil reduced its natural vegetation area by 98.2 Mha $\pm 2.27 \%$, increasing its agricultural area by 93.3 Mha $\pm 0.52 \%$ (Figure 3 ), a land conversion unparalleled in the world for the period in analysis ${ }^{14}$, whose driving forces are intrinsically associated with global demands for soy and beef ${ }^{23-26}$. Although most of this conversion, in absolute area, is due to the expansion of pastures, in relative numbers the crop area of the country almost doubled in the same period, with an expansion predominantly in the area of consolidated pastures (existing in 1985 Figure 3a). This dynamics of land occupation is common in the country ${ }^{9}$, since pastures, due to their low initial investment, occupy extensive areas located in regions with little infrastructure, which, if favorable to mechanization, tend to give space to crops in the following years ${ }^{27}$.

Our estimate of land use and land cover indicated a linear growth of the Brazilian pastures until the year 2005, and a subsequent stabilization in absolute area until the end of the analysis period (Figure 1a). However, when analyzing the agricultural expansion in Brazil, it is possible to note that the conversion of natural vegetation to pasture continued even after 2005, while the conversion from pasture to crops increased in the same period (Figure 3a), an indication that the stabilization observed may be related to the balance between the area of expansion and retraction of pastures, resulting in an absolute balance close to zero in the most recent years of the series.

In this sense, in spite of the reduction of deforestation in Brazil (Figure 2a), the expansion of pasture is still responsible for a large part of the conversion of natural vegetation in the Cerrado and Amazon biomes (Figure 2b), a fact that can be explained by development-oriented policies installed in Brazil in the mid-1970s ${ }^{4}$, and the low value of deforested land in agricultural frontier $\operatorname{areas}^{28}$. On the other hand, most of the expansion of agricultural area in the country took place on consolidated pastures, in the Cerrado biome and in the Atlantic Forest, responsible for most of the production of grains and sugarcane ${ }^{9,29}$. Such land use conversion favored the adoption of new technological standards (i.e. more intensive systems with greater return to the producer) by ranchers located in these regions ${ }^{30,31}$.

This conversion dynamic, however, did not affect most of the country's consolidated pastures, as our results indicate that 105.2 Mha $\pm 0.25 \%$ of the Brazilian pastures did not show any change in land use between 1985 and 2018. These areas are likely to be found in regions with low agricultural suitability, thus having a lower opportunity cost related to an eventual conversion to soybean, given the limitations imposed by environmental and infrastructure conditions ${ }^{32-34}$.

With regard to deforestation, our results indicate that forest formations were the most affected in absolute area (52.7 Mha $\pm 0.99 \%$ ), while savanna and grassland formations were the most affected in relative area, with a reduction in vegetation cover of $27.43 \% \pm 1.18 \%$ and $19.04 \% \pm 0.64 \%$, respectively, between 1988 and 2018, mainly affecting the Cerrado, Pantanal, and Caatinga biomes ${ }^{35-38}$. This can be explained by the negligence of the Brazilian state in monitoring deforestation in the country's non-forest formations, instituting the PRODES Cerrado only in $2016^{5}$, more than two decades after the beginning of PRODES Amazônia, the system responsible for monitor only forest formations in the Legal Amazon ${ }^{39}$.

Specifically in the Legal Amazon, the period from 2008 to 2014 had the smallest deforested areas (see Supplementary Fig. S1a), which may be due to the soy moratorium, an agreement signed by large traders aiming at banning the purchase of production from areas deforested after $2006^{40,41}$. Also noteworthy is the Action Plan for the Prevention and Control of Deforestation in the Legal Amazon, developed in 2004, which sought to promote land and territorial planning, with an allocation of 25 Mha for the creation of new federal Conservation Units and 10 Mha for the demarcation of Indigenous Lands; similarly, monitoring and controlling deforestation through alert and surveillance systems resulted in a drop of about $60 \%$ in the annual rate of deforestation from 1996 to $2016^{42-44}$. However, from 2012 onwards, our results indicate an increase in deforestation in forest formations in the Legal Amazon, which may be related to the beginning of a period of greater political, social, and economic instability in the country ${ }^{8}$. 
In the Cerrado, deforestation did not follow the same downward trend (see Supplementary Fig. S1b). Between 2010 and 2013, the suppression of native areas in the biome surpassed the Legal Amazon, a fact that can be explained by less severe environmental restrictions, lack of monitoring systems and insufficient inspection actions ${ }^{29,45}$, as well as the prevalence of expanding agricultural frontiers ${ }^{6,46,47}$. In view of this favorable scenario for its occupation, in 2013 the biome surpassed the impressive mark of $50 \%$ of its territory anthropized ${ }^{5}$.

When analyzing the entire national territory, almost 35\% are anthropized, and even though our data indicate a trend towards a reduction in deforestation, almost 10 Mha of pastures were abandoned and currently present a high presence of secondary vegetation. In the same period of analysis, we found that $9.64 \mathrm{Mha} \pm 0.45 \%$ of native vegetation were converted to crop, thus suggesting that better use of already open land could prevent the deforestation of new areas. In fact, the use of new management and production techniques are more efficient in terms of productivity than the expansion of new agricultural and livestock areas, thus avoiding underutilization and possible land abandonment ${ }^{48}$. Likewise, and in addition to the preservation and restoration of native vegetation, practices such as more intensive and technified management, combined with the recovery of degraded pastures, can contribute to the preservation of the Brazilian biomes ${ }^{49}$. Also noteworthy is the incorporation of low-carbon technologies (e.g. crop-livestock-forest integration; biological nitrogen fixation; no-till), providing an increase in crop productivity ${ }^{50}$.

\section{Methods}

In this study we used a set of statistical analysis applied to point samples labeled with different Land Use and Land Cover (LULC) classes, derived from the visual interpretation of Landsat images obtained between 1985 and 2018, to produce unbiased and reliable area estimations for Brazil since 1985 (Figure 4). Seeking to provide a dataset adequate to generate independent analyzes, the sample design was developed considering random sampling stratified by the terrain slope and the topographic charts defined by the Brazilian Institute of Geography and Statistics-IBGE ( ${ }^{51}$ - see Supplementary Fig. S2-3). The visual interpretation of the 85,152 samples (see Supplementary Fig. S4) considered a labeling criteria established for each LULC and Brazilian Biome and periodic training involving the team of interpreters. Using the final labeled samples, we produced area estimations, with the Horvitz-Thompson estimator, for 13 LULC classes (i.e. annual crops, forest formation, grasslands formation, other non-forest natural formations, others, pasture, perennial crops, savanna formation, semi-perennial crops, tree plantation, urban infrastructure, water, wetland), historical deforestation, and agricultural expansion for the entire national territory (according to six biomes) over 34 years (from 1985 to 2018).

\section{Sampling Plan}

The sampling planning was built looking for a parsimonious relationship between availability of human resources, time, reliability, and inferential precision. In the sampling design, the population (i.e. the total amount of 30x30m pixels needed to cover the entire Brazilian territory) was divided into domains/sub-populations defined by the grouping of four IBGE topographic charts $^{51}$, named "grouped chart", totaling 127 domains (see Supplementary Fig. S2). These domains were used as the smallest area for which a precision control of proportion estimates with confidence intervals was performed. For each grouped chart a proportional stratified probabilistic sampling of one stage was performed, where the stratification was defined by dividing the grouped chart into six slope classes adopted by the Brazilian Agricultural and Research Organization (EMBRAPA ${ }^{52}$ ), and within each stratum a simple random sampling of the primary sampling units (i.e. pixels) was conducted.

The reliability and precision of the estimates were controlled in each grouped chart, in such a way that the sample size was dimensioned in order to guarantee a maximum margin of error of 5\% and a confidence level of $95 \%$. From this perspective, the maximum error expected for the entire national territory was $0.5 \%$. Thus, and considering the inspection capacity, a minimum quantity of 500 points was defined for each grouped chart. In calculating the sample size, information on the variability and number of land cover and land use classes in each grouped chart was also taken into account, using as a reference the mapping done by Mapbiomas, referring to Collection 3 for the year $2015^{7}$ (see Supplementary Fig. S3). Thus, the sample size was established as an increasing function in relation to the number of classes and/or variability, in order to maintain the same level of confidence and margin of error. The variability information was derived from the maximum variance of the land use and land cover classes, and to consider the information on the number of classes, the Bonferroni correction ${ }^{53}$ was applied, which adjusts the value of the quantile of the standard normal distribution.

Thus, the sample consisted of 85,152 points distributed throughout Brazil, which were drawn by simple random sampling in each grouped chart, resulting in 35,258 points for the Amazon biome, 21,290 for the Cerrado biome, 9,738 for the Caatinga biome, 14,497 for the Atlantic Forest biome, 2,008 for the Pantanal biome, and 2,361 for the Pampa biome (see Supplementary Fig. S4). 


\section{Reference Data and Software Infrastructure}

The spatial unit of this study was a Landsat pixel, with a spatial resolution of $30 \mathrm{~m}$, and the main source of information for classification of land use and land cover was the historical collection of Landsat images, covering a period of 34 years (i.e. 1985 to 2018). The classification was generated through the visual interpretation of images obtained by the Landsat satellite series with less atmospheric interference (according to the CLOUD_COVER metadata) for the dry (i.e. June to October) and rainy (i.e. January to May) periods, using the NIR, SWIR1, RED false-color compositing. The interpretation took place via the Temporal Visual Inspection - TVI, an open source tool developed by the Image Processing and GIS Lab at the Federal University of Goiás (Lapig / UFG), which allows for greater flexibility in the analysis of sampling points with reference to historical series of satellite images (Figures S5-6).

\section{Reference Labeling Protocol}

The point samples were classified into 20 LULC classes, compatible with collection 3 of the MapBiomas project ${ }^{7}$ (see Supplementary Table S1), for which specific Landsat image interpretation criteria were established for each Brazilian biome (e.g. color, shades, texture, homogeneity, form, and context - accessible at: https://lapig.iesa.ufg.br/chave/en/), thus seeking to reduce the subjective aspects inherent to this process. Each sample was evaluated by three distinct interpreters, so that the final class was defined by a majority vote (i.e. the class with two or three votes). For samples with complete disagreement (i.e. assignment of three different classes), the final class was established a posteriori by a fourth supervisor-interpreter.

\section{Area Estimation}

For the area estimates in the study, forest, savanna, and grassland formations were considered as "Native Vegetation"; as "Agriculture" the annual, perennial, and semi-perennial crops; and as "others" the classes of rock outcrops, apicum, aquaculture, mangroves, mining, other non-vegetated areas, beaches, and dunes. After this grouping, the area estimates were calculated according to the reference value assigned to each pixel. For each class of interest, the i-th inspected pixel received the reference value, such that: if equals 1 , it belongs to the class of interest, otherwise it is equal to 0 . Then, an unbiased estimator of the proportion was used to calculate the area estimate of each class of LULC and LULC change. In order to assess whether the stratified sampling (SS) by relief and grouped chart produced a gain in the accuracy (of estimates of the proportions of the studied classes) in relation to a simple random sampling without replacement, we performed an analysis of the Sampling Plan Effect (SPE) based on the comparison of variances and standard errors of estimates (Figures S7-8).

\section{References}

1. Associação Brasileira das Indústrias Exportadoras de Carne. Beef report: Perfil da pecuária do brasil 2020. http: //abiec.com.br/publicacoes/beef-report-2020 (2020).

2. Malafaia, G. C., Biscola, P. H. N. \& Dias, F. R. T. Os impactos da covid-19 para a cadeia produtiva da carne bovina brasileira. Embrapa: Comun. Técnico 154, 1-8 (2020).

3. Sun, Z., Scherer, L., Tukker, A. \& Behrens, P. Linking global crop and livestock consumption to local production hotspots. Glob. Food Secur. 25, 100323, DOI: 10.1016/j.gfs.2019.09.008 (2020).

4. Lapola, D. M. et al. Pervasive transition of the brazilian land-use system. Nat. Clim. Chang. 4, 27-35, DOI: 10.1038/ nclimate2056 (2013).

5. Parente, L. et al. Quality assessment of the PRODES cerrado deforestation data. Remote. Sens. Appl. Soc. Environ. 21, 100444, DOI: 10.1016/j.rsase.2020.100444 (2021).

6. de Mattos Scaramuzza, C. A. et al. Land-use and land-cover mapping of the brazilian cerrado based mainly on landsat-8 satellite images. Revista Brasileira de Cartografia 69 (2017).

7. Souza, C. M. et al. Reconstructing three decades of land use and land cover changes in brazilian biomes with landsat archive and earth engine. Remote. Sens. 12, 2735, DOI: 10.3390/rs12172735 (2020).

8. Carvalho, W. D. et al. Deforestation control in the brazilian amazon: A conservation struggle being lost as agreements and regulations are subverted and bypassed. Perspectives Ecol. Conserv. 17, 122-130, DOI: 10.1016/j.pecon.2019.06.002 (2019).

9. Parente, L., Mesquita, V., Miziara, F., Baumann, L. \& Ferreira, L. Assessing the pasturelands and livestock dynamics in brazil, from 1985 to 2017: A novel approach based on high spatial resolution imagery and google earth engine cloud computing. Remote. Sens. Environ. 232, 111301, DOI: 10.1016/j.rse.2019.111301 (2019).

10. Barona, E., Ramankutty, N., Hyman, G. \& Coomes, O. T. The role of pasture and soybean in deforestation of the brazilian amazon. Environ. Res. Lett. 5, 024002, DOI: 10.1088/1748-9326/5/2/024002 (2010). 
11. Clark, M. A. et al. Global food system emissions could preclude achieving the $1.5^{\circ}$ and $2^{\circ} \mathrm{c}$ climate change targets. Science 370, 705-708, DOI: 10.1126/science.aba7357 (2020).

12. Rajão, R. et al. The rotten apples of brazil's agribusiness. Science 369, 246-248, DOI: 10.1126/science.aba6646 (2020).

13. Diniz, C. G. et al. DETER-b: The new amazon near real-time deforestation detection system. IEEE J. Sel. Top. Appl. Earth Obs. Remote. Sens. 8, 3619-3628, DOI: 10.1109/jstars.2015.2437075 (2015).

14. Song, X.-P. et al. Global land change from 1982 to 2016. Nature 560, 639-643, DOI: 10.1038/s41586-018-0411-9 (2018).

15. Hansen, M. C. et al. High-resolution global maps of 21 st-century forest cover change. Science 342, 850-853, DOI: 10.1126/science.1244693 (2013).

16. Stehman, S. V. \& Foody, G. M. Key issues in rigorous accuracy assessment of land cover products. Remote. Sens. Environ. 231, 111199, DOI: 10.1016/j.rse.2019.05.018 (2019).

17. Lopes, V. C., Parente, L. L., Baumann, L. R. F., Miziara, F. \& Ferreira, L. G. Land-use dynamics in a brazilian agricultural frontier region, 1985-2017. Land Use Policy 97, 104740, DOI: 10.1016/j.landusepol.2020.104740 (2020).

18. Tyukavina, A. et al. Types and rates of forest disturbance in brazilian legal amazon, 2000-2013. Sci. Adv. 3, e1601047, DOI: 10.1126/sciadv.1601047 (2017).

19. King, L. et al. A multi-resolution approach to national-scale cultivated area estimation of soybean. Remote. Sens. Environ. 195, 13-29, DOI: 10.1016/j.rse.2017.03.047 (2017).

20. Olofsson, P. et al. Good practices for estimating area and assessing accuracy of land change. Remote. Sens. Environ. 148, 42-57, DOI: 10.1016/j.rse.2014.02.015 (2014).

21. Zalles, V. et al. Rapid expansion of human impact on natural land in south america since 1985. Sci. Adv. 7, eabg1620, DOI: 10.1126/sciadv.abg1620 (2021).

22. Stehman, S. V. Estimating area and map accuracy for stratified random sampling when the strata are different from the map classes. Int. J. Remote. Sens. 35, 4923-4939, DOI: 10.1080/01431161.2014.930207 (2014).

23. Bahar, N. H. et al. Meeting the food security challenge for nine billion people in 2050: What impact on forests? Glob. Environ. Chang. 62, 102056, DOI: 10.1016/j.gloenvcha.2020.102056 (2020).

24. de Arruda, M. R., Slingerland, M., Santos, J. Z. L. \& Giller, K. E. Agricultural land use change and associated driving forces over the past 180 years in two municipalities of the brazilian cerrado. GeoJournal 84, 555-570, DOI: 10.1007/s10708-018-9875-2 (2018).

25. Richards, P., Pellegrina, H., VanWey, L. \& Spera, S. Soybean development: The impact of a decade of agricultural change on urban and economic growth in mato grosso, brazil. PLOS ONE 10, e0122510, DOI: 10.1371/journal.pone.0122510 (2015).

26. Foley, J. A. et al. Solutions for a cultivated planet. Nature 478, 337-342, DOI: 10.1038/nature10452 (2011).

27. Parente, L. \& Ferreira, L. Assessing the spatial and occupation dynamics of the brazilian pasturelands based on the automated classification of MODIS images from 2000 to 2016. Remote. Sens. 10, 606, DOI: 10.3390/rs10040606 (2018).

28. Bowman, M. S. et al. Persistence of cattle ranching in the brazilian amazon: A spatial analysis of the rationale for beef production. Land Use Policy 29, 558-568, DOI: 10.1016/j.landusepol.2011.09.009 (2012).

29. Maranhão, R. L. A. et al. The spatiotemporal dynamics of soybean and cattle production in brazil. Sustainability 11, 2150, DOI: $10.3390 /$ su11072150 (2019).

30. Dias, L. C. P., Pimenta, F. M., Santos, A. B., Costa, M. H. \& Ladle, R. J. Patterns of land use, extensification, and intensification of brazilian agriculture. Glob. Chang. Biol. 22, 2887-2903, DOI: 10.1111/gcb.13314 (2016).

31. Verhulst, N. et al. Conservation agriculture, improving soil quality for sustainable production systems? In Food Security and Soil Quality, 137-208, DOI: 10.1201/ebk1439800577-7 (CRC Press, 2010).

32. Pimenta, F. M., Speroto, A. T., Costa, M. H. \& Dionizio, E. A. Historical changes in land use and suitability for future agriculture expansion in western bahia, brazil. Remote. Sens. 13, 1088, DOI: 10.3390/rs13061088 (2021).

33. Cohn, A. S., Gil, J., Berger, T., Pellegrina, H. \& Toledo, C. Patterns and processes of pasture to crop conversion in brazil: Evidence from mato grosso state. Land Use Policy 55, 108-120, DOI: 10.1016/j.landusepol.2016.03.005 (2016).

34. Morton, D. C. et al. Reevaluating suitability estimates based on dynamics of cropland expansion in the brazilian amazon. Glob. Environ. Chang. 37, 92-101, DOI: 10.1016/j.gloenvcha.2016.02.001 (2016). 
35. ALHO, C. J. R., MAMEDE, S. B., BENITES, M., ANDRADE, B. S. \& SEPÚLVEDA, J. J. O. THREATS TO THE BIODIVERSITY OF THE BRAZILIAN PANTANAL DUE TO LAND USE AND OCCUPATION. Ambiente \& Sociedade 22, DOI: 10.1590/1809-4422asoc201701891vu201913ao (2019).

36. de Oliveira, T. E. et al. Agricultural land use change in the brazilian pampa biome: The reduction of natural grasslands. Land Use Policy 63, 394-400, DOI: 10.1016/j.landusepol.2017.02.010 (2017).

37. Strassburg, B. B. N. et al. Moment of truth for the cerrado hotspot. Nat. Ecol. \& Evol. 1, DOI: 10.1038/s41559-017-0099 (2017).

38. Beuchle, R. et al. Land cover changes in the brazilian cerrado and caatinga biomes from 1990 to 2010 based on a systematic remote sensing sampling approach. Appl. Geogr. 58, 116-127, DOI: 10.1016/j.apgeog.2015.01.017 (2015).

39. Shimabukuro, Y. E., dos Santos, J. R., Formaggio, A. R., Duarte, V. \& Rudorff, B. F. T. The brazilian amazon monitoring program: Prodes and deter projects. Glob. For. Monit. from Earth Obs. edited by F. Achard, MC Hansen 153-169 (2012).

40. Heilmayr, R., Rausch, L. L., Munger, J. \& Gibbs, H. K. Brazil's amazon soy moratorium reduced deforestation. Nat. Food 1, 801-810, DOI: 10.1038/s43016-020-00194-5 (2020).

41. Rudorff, B. F. T. et al. The soy moratorium in the amazon biome monitored by remote sensing images. Remote. Sens. 3 , 185-202, DOI: 10.3390/rs3010185 (2011).

42. Ministério do Meio Ambiente, Secretaria de Mudança do Clima e Florestas, Departamento de Florestas e Combate ao Desmatamento. Plano de ação para prevenção e controle do desmatamento e das queimadas no cerrado (ppcerrado) e plano de ação para prevenção e controle do desmatamento na amazônia legal (ppcdam) : fase 2016-2020. http://combateaodesmatamento.mma.gov.br/images/Doc_ComissaoExecutiva/Livro-PPCDam-e-PPCerrado_ 20JUN2018.pdf (2018).

43. Kastens, J. H., Brown, J. C., Coutinho, A. C., Bishop, C. R. \& Esquerdo, J. C. D. M. Soy moratorium impacts on soybean and deforestation dynamics in mato grosso, brazil. PLOS ONE 12, e0176168, DOI: 10.1371/journal.pone.0176168 (2017).

44. Boucher, D., Roquemore, S. \& Fitzhugh, E. Brazil's success in reducing deforestation. Trop. Conserv. Sci. 6, 426-445, DOI: $10.1177 / 194008291300600308$ (2013).

45. le Polain de Waroux, Y. et al. The restructuring of south american soy and beef production and trade under changing environmental regulations. World Dev. 121, 188-202, DOI: 10.1016/j.worlddev.2017.05.034 (2019).

46. de Araújo, M. L. S. et al. Spatiotemporal dynamics of soybean crop in the matopiba region, brazil (1990-2015). Land Use Policy 80, 57-67, DOI: 10.1016/j.landusepol.2018.09.040 (2019).

47. Rausch, L. L. et al. Soy expansion in brazil's cerrado. Conserv. Lett. 12, DOI: 10.1111/conl.12671 (2019).

48. Garrett, R. et al. Intensification in agriculture-forest frontiers: Land use responses to development and conservation policies in brazil. Glob. Environ. Chang. 53, 233-243, DOI: 10.1016/j.gloenvcha.2018.09.011 (2018).

49. Spera, S. Agricultural intensification can preserve the brazilian cerrado: Applying lessons from mato grosso and goiás to brazil's last agricultural frontier. Trop. Conserv. Sci. 10, 194008291772066, DOI: 10.1177/1940082917720662 (2017).

50. de Moraes Sá, J. C. et al. Low-carbon agriculture in south america to mitigate global climate change and advance food security. Environ. Int. 98, 102-112, DOI: 10.1016/j.envint.2016.10.020 (2017).

51. MELO, D., Volpi, E. M., da Silva, H. M., Menezes, L. A. \& Moura, P. V. Aquisição e leitura da carta topográfica digital do ibge. Geografia (Londrina). Londrina: UEL 23, 191-204 (2014).

52. Dos Santos, H. et al. Brazilian soil classification system. Embrapa Solos-Livro técnico (INFOTECA-E) (2018).

53. Köhl, M., Magnussen, S., Marchetti, M. et al. Sampling methods, remote sensing and GIS multiresource forest inventory (Springer, 2006).

54. IBGE \& IBGE. Biomas e sistema costeiro-marinho do brasil: compatível com a escala 1: 250000 (2019).

\section{Data Availability}

The final sampling dataset with all the classes, sampling probability, and weights is publicly available at https://doi.org/ 10.5281 / zenodo 5136666 under the Creative Commons License, which, despite its limitations, can contribute to several initiatives of LULC monitoring in Brazil. The TVI source code and the area estimator implementation are available at https: //github.com/lapig-ufg/tvi and https://github.com/lapig-ufg/tvi-analysis, respectively, both under the MIT license. 
${ }_{341}$ Competing interests

342 The author(s) declare no competing interests.

\section{Acknowledgements} (CAPES), and the Brazilian Research Council (CNPq).

\section{Author contributions statement}

This work, part of the MapBiomas initiative (http: / / mapbiomas . org), was supported by the Gordon and Betty Moore Foundation (GBMF), The Nature Conservancy (TNC), the Coordination for the Improvement of Higher Education Personnel

L.P., L.F., and A.M. conceived the idea of the study and, together with L.B., devised the methodological approach. A.M., E.S., V.M. and S.N. supervised the image interpretation work. A.M., V.M., L.P. and V.L. organized and processed the data and, together with L.B. and L.F., analyzed the results. All the authors contributed to the discussions and writing or revision of the manuscript. L.F. was responsible for the funding acquisition. 

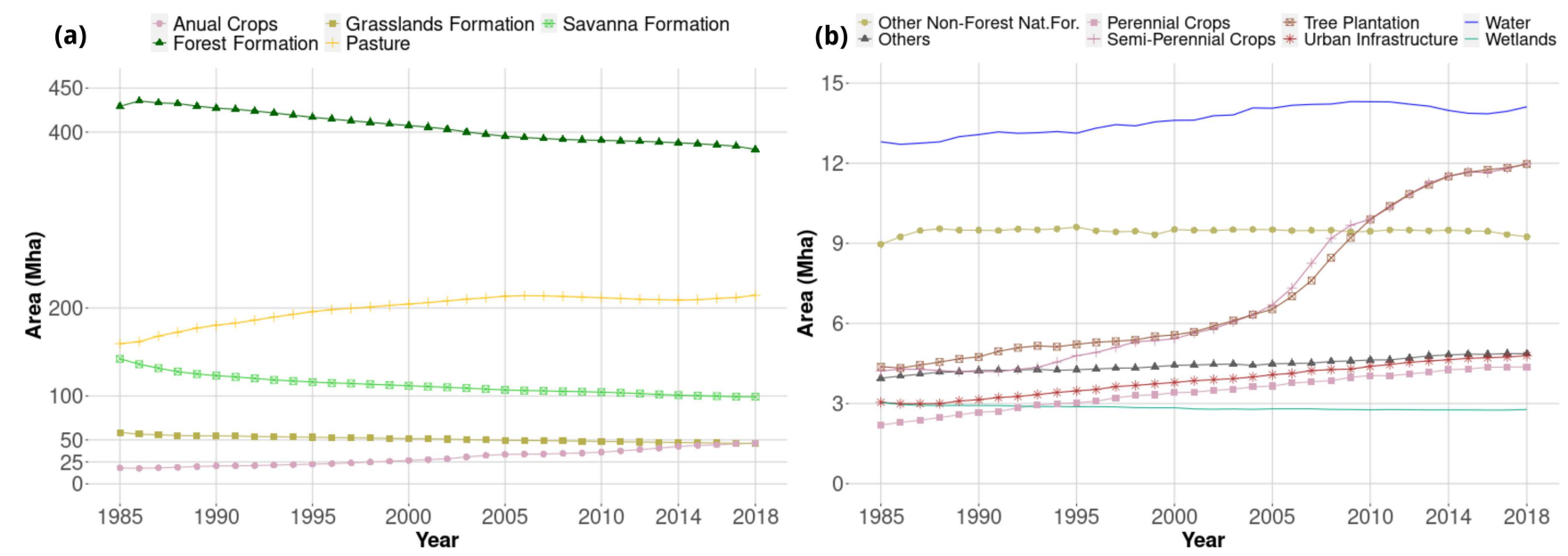

Figure 1. Annual area estimation for the land use and land cover classes greater than $15 \mathrm{Mha}$ (a), and less than $15 \mathrm{Mha}$ (b) for Brazil, between 1985 and 2018. The estimated standard error varied between 0.04\% (perennial crops in 1986) and 0.37\% (forest formation in 1985).
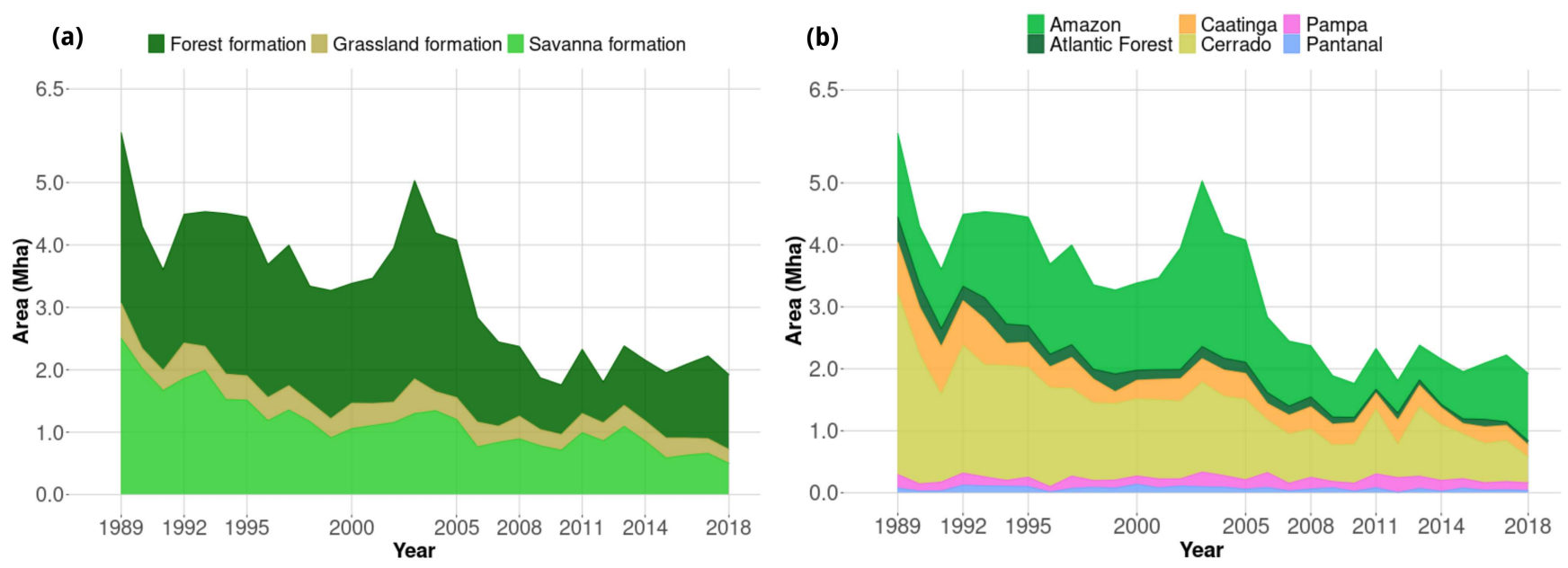

Figure 2. Estimated area for primary deforestation (i.e. first vegetation suppression event), using as baseline 1988, in the main vegetation formations of Brazil (a) and in the six Brazillian biomes ( $b$ - considering the new boundaries defined by ${ }^{54}$ ). 


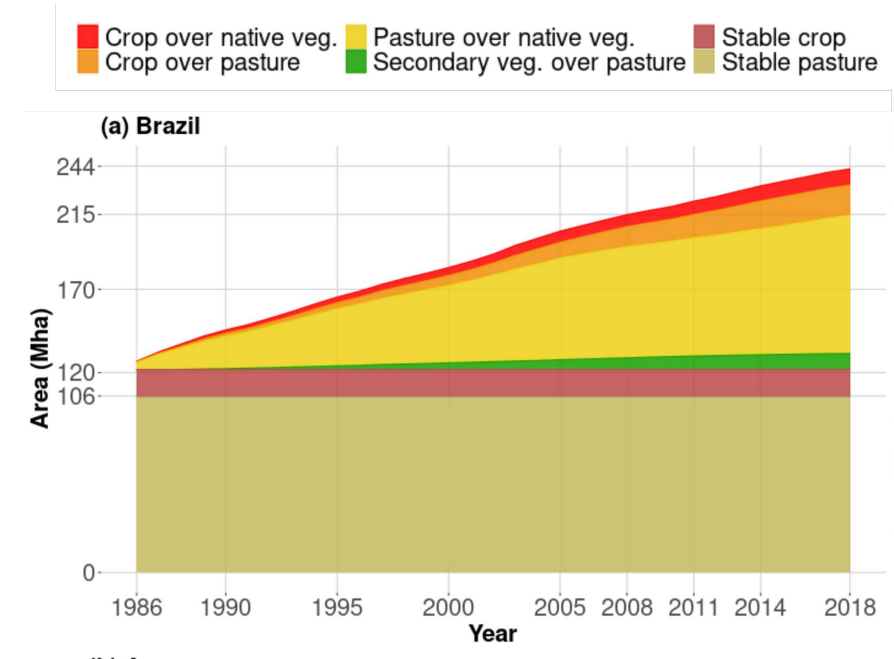

\section{(d) Atlantic Forest}

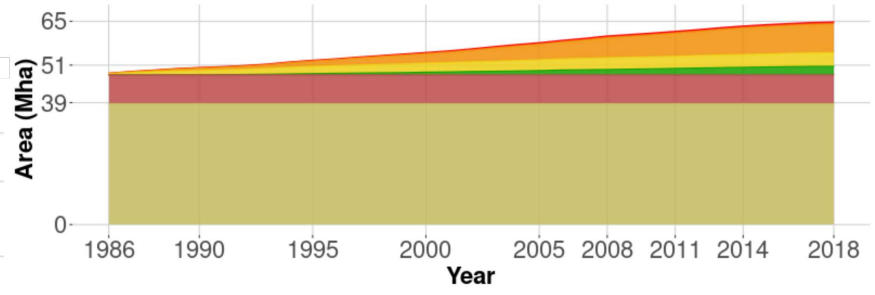

(e) Caatinga
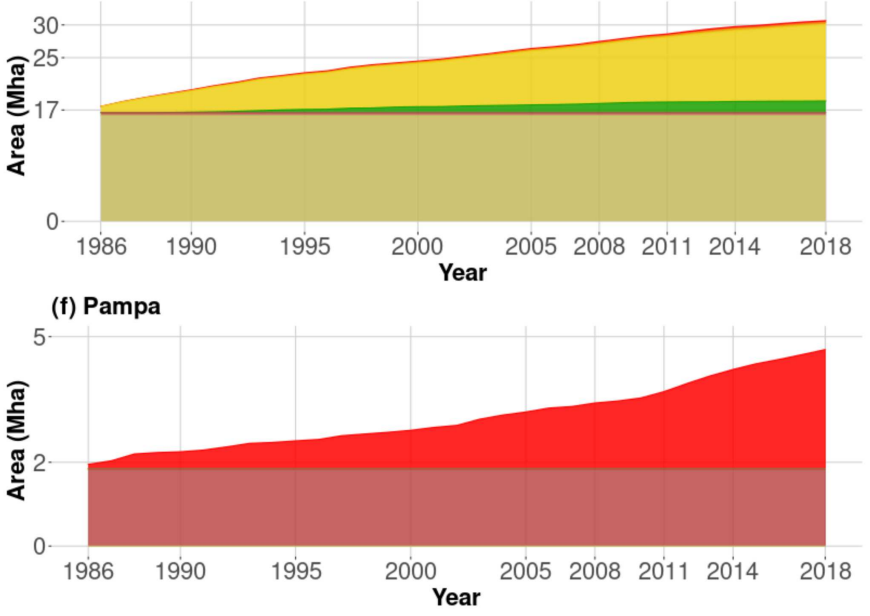

(g) Pantanal

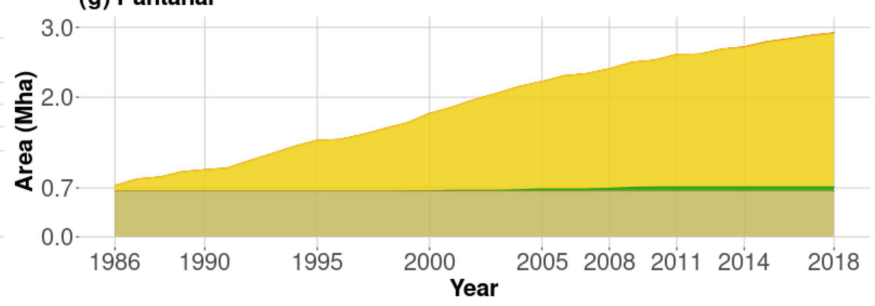

Figure 3. Stable area of pasture and crop (i.e. without LULC-change between 1986 and 2018), and the cumulative area of crop expansion over native vegetation and pasture, pasture expansion over native vegetation, and secondary vegetation over pasture in (a) Brazil and in the six Brazilian biomes (b-g). For the estimates of native vegetation, all the vegetation formation (i.e. forest, savanna and grasslands) were considered. 


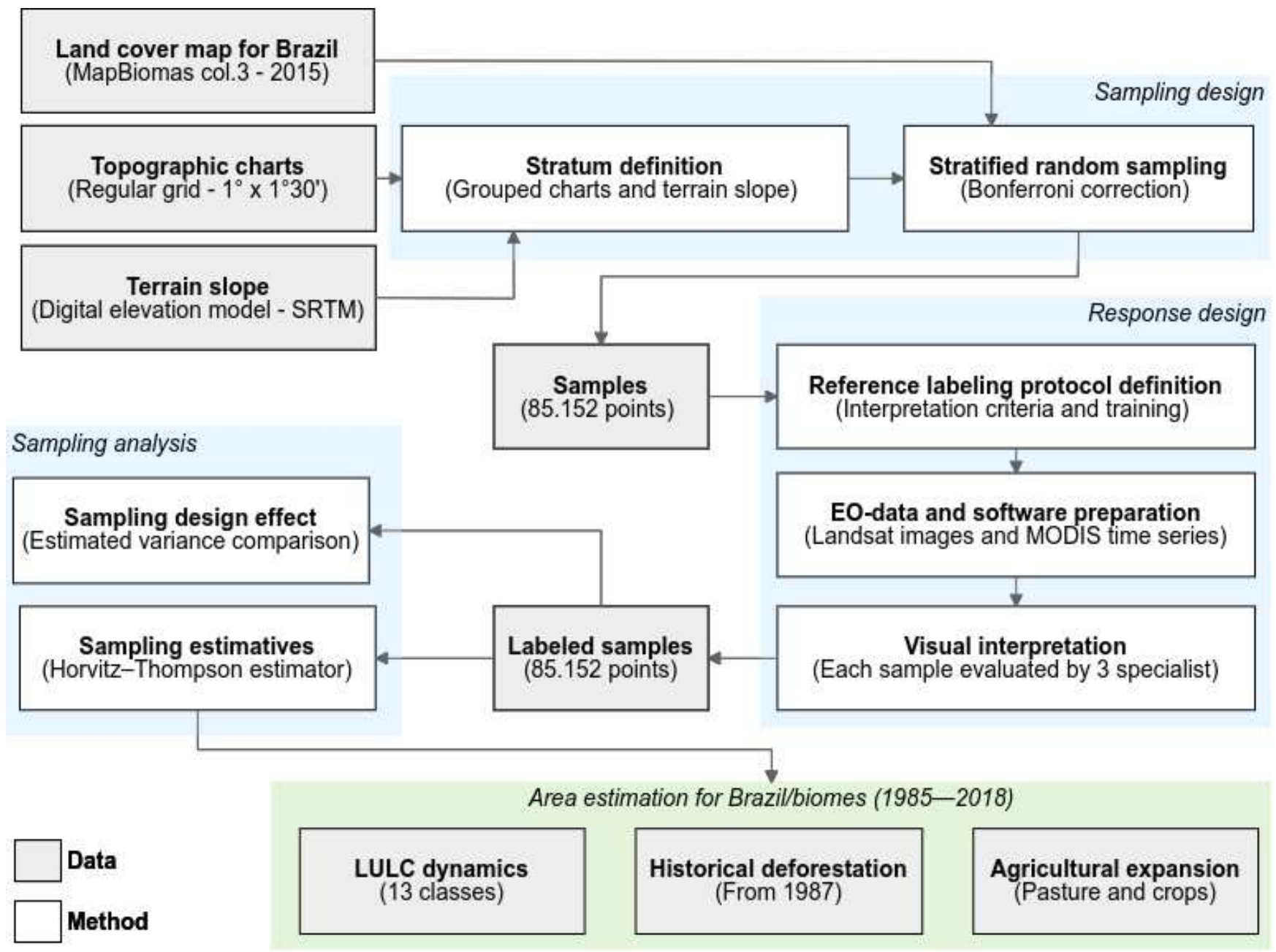

Figure 4. Methodological approach used to design and label 85,152 point samples produced by this study. Based on it, we estimated areas for 13 LULC classes (e.g. Annual Crops, Forest Formation, Grasslands Formation, Pasture), historical deforestation and agriculture expansion (e.g. stable pasture, secondary vegetation over pasture, crop over native vegetation) for the entire national territory (according to six biomes) over 34 years (1985 until 2018). 


\section{Supplementary Files}

This is a list of supplementary files associated with this preprint. Click to download.

- supplementaryinformation.pdf 